\title{
MAPS ON OPERATORS STRONGLY PRESERVING SHARP ORDER
}

\author{
M. A. EFimov And A. E. Guterman
}

Abstract. We discuss the structure of additive transformations on $B(H)$ that are strongly monotone with respect to the $\stackrel{\sharp}{\leqslant}$-order and characterize them under the assumption of bijectivity. We also characterize bijective transformations on the sets of linear combinations of idempotents in $B(H)$ that are strongly monotone with respect to the $\stackrel{\#}{\leqslant}$-order.

Mathematics subject classification (2010): 15A43, 15A15.

Keywords and phrases: Monotone transformations, Hilbert space, group inverse.

\section{REFERENCES}

[1] A. Alieva, A. Guterman, Monotone linear transformations on matrices are invertible, Comm. in Algebra, 33 (2005), 3335-3352.

[2] A. Ben-Israel, T. Greville, Generalized Inverses: Theory and Applications, New York: Hohn Wiley and Sons. 1974.

[3] I. I. Bogdanov, A. E. Guterman, Monotone matrix maps defined by the group inverse and simultaneous diagonalizability, Matematicheskii Sbornik, 198, 1 (2007), 3-20 [in Russian].

[4] M. Bohata, J. Hamhalter, Nonlinear maps on von Neumann algebras preserving the star order, Linear and Mult. Algebra, 61, 7 (2013), 998-1009.

[5] M. Bohata, J. Hamhalter, Star order on JBW algebras, J. Math. Anal. Appl. 417, 2 (2014), 873-888.

[6] Ch. Deng, Sh. WAng, On some characterizations of the partial orderings for bounded operators, Math. Inequal. Appl. 15, 3 (2012), 619-630.

[7] G. Dolinar, A. Guterman, J. Marovt, Automorphisms of $K(H)$ with respect to the star partial order, Operators and Matrices, 7, 1 (2013), 225-239.

[8] G. Dolinar, A. Guterman, J. Marovt, Monotone transformations on B $(H)$ with respect to the left-star and the right-star partial order, Mathematical Inequalities and Applications, 17, 2 (2014), 573-589.

[9] G. Dolinar, J. Marovt, Star partial order on B(H), Linear Algebra Appl., 434 (2011), 319-326.

[10] M. A. EFIMOV, Additive matrix maps that are monotone with respect to the orders induced by group inverse, Fundamentalnaya i Prikladnaya Matematika, 17, 6 (2011/2012), $23-40$ [in Russian]. Translated in Journal of Mathematical Sciences (New-York), 193, 5 (2013), 659-670.

[11] M. A. Efimov, Linear matrix transformations that are monotone with respect to the $\stackrel{\sharp}{\leqslant}$ - or $\stackrel{c n}{\leqslant}$-order, Fundamentalnaya i Prikladnaya Matematika, 13, 4 (2007), 53-66 [in Russian]. Translated in Journal of Mathematical Sciences (New-York), 155, 6 (2008), 830-838.

[12] M. A. EFIMOV, On the $\stackrel{\sharp}{\leqslant}$-order on the set of linear bounded operators in Banach space, Matematicheskie Zametki, 93, 5 (2013), 794-797 [in Russian]. Translated in Mathematical Notes, 93, 5 (2013), 784-788.

[13] M. A. Efimov, A. E. Guterman, Monotone maps on diagonalizable matrices, Mathematical Inequalities and Applications, 17, 4, (2014) 1441-1452.

[14] M. A. Efimov, A. E. Guterman, Monotone maps on index one matrices, Zapiski POMI, 405 (2012), 67-96 [in Russian]. Translated in Journal of Mathematical Sciences (New-York), 191, 1 (2013), 36-51. 
[15] J. HAMHALTER, Isomorphisms of ordered structures of abelian $C_{*}$-subalgebras of $C_{*}$-algebras, J. Math. Anal. Appl. 383, 2 (2011), 391-399.

[16] J. HAmHalteR, E. TURILOVA, Automorphisms of order structures of abelian parts of operator algebras and their role in quantum theory, Internat. J. Theoret. Phys. 53, 10 (2014), 3333-3345.

[17] R. E. HARTwig, How to partially order regular elements, Math. Japonica, 25, 1 (1980), 1-13.

[18] R. E. Hartwig, S. K. Mitra, Partial orders based on outer inverses, Linear Algebra Appl., 176 (1982), 3-20.

[19] P. LEGIŠA, Automorphisms of $M_{n}$, partially ordered by rank subtractivity ordering, Linear Algebra Appl., 389 (2004), 147-158.

[20] P. LEGIŠA, Automorphisms of $M_{n}$, partially ordered by the star order, Linear and Mult. Algebra, 54, 3 (2006), 157-188.

[21] J. MAROVt, D. S. RAKiĆ, D. S. DJoRdjeVIĆ, Star, left-star, and right-star partial orders in Rickart *-rings, Linear and Mult. Algebra, 63, 2 (2015), 343-365.

[22] S. K. Mitra, On group inverses and the sharp order, Linear Algebra Appl., 92 (1987), 17-37.

[23] S. K. Mitra, P. Bhimasankaram, S. B. Malik, Matrix Partial Orders, Shorted Operators and Applications, World Scientific Publishing Company. 2010.

[24] M. Z. NAShed (Ed.), Generalized inverses and applications, Academic Press, New York-London, 1976.

[25] P. G. Ovchinnikov, Automorphisms of the poset of skew projections, J. of Functional Analysis, 115 (1993), 184-189.

[26] J. DE PILLIS, Linear transformations which preserve Hermitian and positive semidefinite operators, Pacific J. of Math., 23 (1967), 129-137.

[27] D. S. RAKIĆ, D. S. DJORDJEVIĆ, Space pre-order and minus partial order for operators on Banach spaces, Aequationes Math. 85, 3 (2013), 429-448.

[28] P. ŠEMrL, Order-preserving maps on the poset of idempotent matrices, Acta Sci. Math. (Szeged), 63 (2003), 481-490.

[29] P. ŠEMRL, Automorphisms of $B(H)$ with respect to minus partial order, J. Math. Anal. Appl, 369 (2010), 205-213. 